\title{
Microwave Synthesis of a Porous Metal-Organic Framework, Nickel(II) Dihydroxyterephthalate and its Catalytic Properties in Oxidation of Cyclohexene
}

\author{
Ji Sun Lee, Shiva B. Halligudi, Nak Han Jang, ${ }^{\dagger}$ Dong Won Hwang, Jong-San Chang, and Young Kyu Hwang* \\ Catalysis Center for Molecular Engineering (CCME), Korea Research Institute of Chemical Technology (KRICT), \\ Daejeon 305-600, Korea. ${ }^{*}$ E-mail: ykhwang@krict.re.kr \\ ${ }^{\dagger}$ Department of Chemistry Education, Kongju National University, Chungnam 314-701, Korea \\ Received December 3, 2009, Accepted February 25, 2010
}

\begin{abstract}
A porous coordination solid of nickel(II) dihydroxyterephthalate has been synthesized by the microwave-assisted (MW) method. The synthesized nickel(II) dihyroxylterephthalate was designated by the general formula of [ $\mathrm{Ni}_{2}(\mathrm{dhtp})$ $\left.\left(\mathrm{H}_{2} \mathrm{O}\right)_{2}\right] \cdot 8 \mathrm{H}_{2} \mathrm{O}$ (where, dhtp = 2,5-dihydroxyterephthalate, denoted by Ni-DHTP). The effect of microwave-irradiation temperature and time of irradiation on the porosity and morphological changes in the solids have also been investigated. The catalytic performance of Ni-DHTP synthesized by MW method has been studied in the oxidation of cyclohexene with aqueous $\mathrm{H}_{2} \mathrm{O}_{2}$, which gave cyclohexene oxide as the primary product and 2-cyclohexene-1-ol as a major product.
\end{abstract}

Key Words: MOF materials, Ni-CPO-27, Microwave synthesis, Epoxidation, Cyclohexene

\section{Introduction}

The metal-organic frameworks (MOFs) ${ }^{1-5}$ have recently received considerable attention in gas storage, ${ }^{6,7}$ catalysis, ${ }^{8}$ drug delivery $^{9}$ and molecular recognition ${ }^{10}$ because of their excellent crystallinity, tailor-made porosity with high surface area, framework flexibility and bifunctionalities of metal and ligands. Among them, nickel dihydroxyterephthalate $\left[\mathrm{Ni}_{2}(\mathrm{dhtp})\left(\mathrm{H}_{2} \mathrm{O}\right)_{2}\right]$. $8 \mathrm{H}_{2} \mathrm{O}$ (where, dhtp $=2,5$-dihydroxyterephthalate, hereafter denoted by Ni-DHTP which was named by Ni-CPO-27 is one of the frequently studied metal-organic framework (MOF) material because of a large surface area, a relatively high thermal stability and a large number of open metal sites after removal of solvent or water molecules from the framework pores. ${ }^{11-13}$ These properties enable the above material to be a potential candidate for gas sorption and delivery. ${ }^{14-16}$ Since the discovery of Ni-DHTP which has equivalent structure of MOF-74 reported by Rosi et al., ${ }^{17}$ this has been synthesized by conventional hydrothermal or solvothermal method $(\mathrm{CH})$ for improving the purity of crystal. As reported earlier by us, MOFs show a significant difference in porosity and crystallinity depending on the synthetic conditions and preparation method as well as purification procedure. ${ }^{18,19}$ Microwave-assisted hydrothermal or solvothermal synthesis (MW) has significant advantages over $\mathrm{CH}$ synthesis because of rapid heating, faster kinetics, higher yield and better reproducibility. ${ }^{19-23}$ In addition to this, it provides an efficient way to control particle size distribution, phase selectivity and macroscopic morphology in the synthesis of nanoporous materials. ${ }^{24-26}$ Despite these facts, there are only a few reports on the use of microwave for synthesis of porous coordination materials. ${ }^{19,27-30}$ Here, we present the use of microwaves for the synthesis of Ni-DHTP in a much shorter time and lower temperature than reported for the original synthesis via $\mathrm{CH}$ method. ${ }^{11}$

MOFs are porous and crystalline coordination polymers consisting of mainly transition metals, which have recently attracted many researchers to explore the possibilities of their appli- cations in catalytic organic transformations. ${ }^{31-35}$ However, the study on catalytic applications of MOF materials is limited. ${ }^{8,36-40}$ Therefore, besides microwave synthesis, the catalytic activity of Ni-DHTP synthesized by MW method has been studied in the oxidation of cyclohexene with aqueous $\mathrm{H}_{2} \mathrm{O}_{2}$ as oxidant. Ni-DHTP synthesized by MW at different synthesis temperatures and irradiation times has been found to be a good catalyst system for the oxidation of cyclohexene under milder conditions, which gave cyclohexene oxide and 2-cyclohexene-1-ol as the major products under milder oxidation conditions.

\section{Experimental}

Materials. Nickel acetate tetrahydrate, 2,5-dihydroxyterephthalic acid and THF of AR grade were procured from SigmaAldrich Chemicals and were used without purification. Aqueous $\mathrm{H}_{2} \mathrm{O}_{2}(28 \%$ solution) was used as an oxidant in the reaction. Deionized water was used for the synthesis of Ni-DHTP materials by both $\mathrm{CH}$ and $\mathrm{MW}$ methods. Microwave instrument of make MARS-5, CEM operating at $50{ }^{\circ} \mathrm{C}$ to $220{ }^{\circ} \mathrm{C}$ with resistance to autogenic pressure in up to 400 psig and power $600 \mathrm{~W}$ was used in the preparation of catalysts by MW method.

Synthesis of Ni-DHTP. A solution of nickel acetate tetrahydrate $(0.381 \mathrm{~g}, 1.5 \mathrm{mmole})$ in $10 \mathrm{~mL}$ of water and a solution of 2,5-dihydroxyterephthalic acid $(0.152 \mathrm{~g}, 0.75 \mathrm{mmole})$ in 10 $\mathrm{mL}$ of THF were mixed in a teflon vessel. The autoclave was loaded in a microwave oven (MARS-5, CEM with $600 \mathrm{~W}$ ) and heated at $90,110,130{ }^{\circ} \mathrm{C}$ from $2 \mathrm{~min}$ to $1 \mathrm{~h}$, respectively. After the completion of the reaction, the mixtures were allowed to cool down to room temperature, filtered and washed with water and ethanol mixture several times and were dried at $100{ }^{\circ} \mathrm{C}$ overnight. In this work, the as-synthesized samples obtained by microwave method at 90,110 , and $130{ }^{\circ} \mathrm{C}$ for $1 \mathrm{~h}$ are denoted by $\mathrm{MW}-90(1 \mathrm{H}), \mathrm{MW}-110(1 \mathrm{H})$, and $\mathrm{MW}-130(1 \mathrm{H})$, respectively. Numbers in parenthesis indicate microwave irradiation time, i.e. $1 \mathrm{H}$ means $1 \mathrm{~h}$. Also two more samples were prepared for checking the effect of irradiation time $2 \mathrm{M}$ and $10 \mathrm{M}$ i.e. $2 \mathrm{M}$ 
Table 1. Physicochemical properties of Ni-DHTP synthesized by MW and CH methods

\begin{tabular}{lccccc}
\hline \multicolumn{1}{c}{ Samples $^{a}$} & Synthesis Method & $\begin{array}{c}\text { Synthesis Temperature } \\
\left({ }^{\circ} \mathrm{C}\right)\end{array}$ & $\begin{array}{c}\text { Synthesis Time } \\
(\mathrm{h} \text { or min })\end{array}$ & $\begin{array}{c}\text { Surface area } \\
\left(\mathrm{m}^{2} / \mathrm{g}\right)\end{array}$ & $\begin{array}{c}\text { Pore volume } \\
(\mathrm{mL} / \mathrm{g})\end{array}$ \\
\hline $\mathrm{CH}-90(72 \mathrm{H})$ & Conventional solvothermal synthesis & 90 & $72 \mathrm{~h}$ & 1157 & 0.64 \\
$\mathrm{CH}-110(72 \mathrm{H})$ & Conventional solvothermal synthesis & 110 & $72 \mathrm{~h}$ & 1226 & 0.65 \\
MW-90(1H) & Microwave synthesis & 90 & $1 \mathrm{~h}$ & 1148 & 0.67 \\
MW-110(1H) & Microwave synthesis & 110 & $1 \mathrm{~h}$ & 1050 & 0.68 \\
MW-130(1H) & Microwave synthesis & 130 & $1 \mathrm{~h}$ & 913 & 0.58 \\
MW-110(2M) & Microwave synthesis & 110 & $2 \mathrm{~min}$ & 774 & 0.54 \\
MW-110(10M) & Microwave synthesis & 110 & 10 min & 908 & 0.57 \\
\hline
\end{tabular}

${ }^{a} \mathrm{CH}=$ Conventional solvothermal synthesis; MW = Microwave synthesis. Note: in CH method, Ni-DHTP did not form as expected at less than $72 \mathrm{~h}$.

means 2 minute, MW-110(2M) and MW-110(10M), respectively. For the sake of comparison, sample was also prepared by $\mathrm{CH}$ method following the known procedure ${ }^{11}$ using the above mixtures at $90^{\circ} \mathrm{C}$ or $110^{\circ} \mathrm{C}$ for $72 \mathrm{~h}$. The as-synthesized samples obtained by conventional solvothermal heating are denoted by $\mathrm{CH}-90(72 \mathrm{H})$ and $\mathrm{CH}-110(72 \mathrm{H})$, respectively. Similarly, numbers in parenthesis indicate synthesis time, i.e. $72 \mathrm{H}$ means $72 \mathrm{~h}$. The physicochemical properties of the Ni-DHTP samples are presented in Table 1.

Characterization of Ni-DHTP. The as-synthesized Ni-DHTP materials by $\mathrm{CH}$ and $\mathrm{MW}$ methods at different temperatures and irradiation times were characterized for their structural integrities by XRD, BET, FT-IR and SEM methods. Specific surface areas of Ni-DHTP were measured by $\mathrm{N}_{2}$ adsorption and desorption isotherms at liquid nitrogen temperature using a sorption analyzer (Micromeritics, Tristar 3000) and standard multipoint BET analysis method. Samples were degassed in flowing $\mathrm{N}_{2}$ for $5 \mathrm{~h}$ at $250^{\circ} \mathrm{C}$ before $\mathrm{N}_{2}$ physisorption measurements. The specific surface areas were evaluated using the Brunauer-Emmett-Teller (BET) method in the $\mathrm{p} / \mathrm{p}_{0}$ range of $0.05 \sim$ 0.2 . Powder X-ray diffraction patterns of all the samples were obtained by a Rigaku diffract meter (D/MAX IIIB, $2 \mathrm{~kW}$ ) using Ni-filtered CuK $\alpha$-radiation $(40 \mathrm{kV}, 30 \mathrm{~mA}, \lambda=1.5406 \AA)$ and a graphite crystal monochromator. The crystal sizes and morphology of the catalysts were examined using a scanning electron microscope (SEM, JEOL JSM-840A).

Catalytic measurements. The oxidation of cyclohexene was performed in a conventional glass reactor $(50 \mathrm{~mL})$ with a condenser and stirrer. In a typical run of catalytic measurement, the reactor was loaded with $0.1 \mathrm{~g}$ catalyst, $5 \mathrm{~mL}$ cyclohexene $(5 \mathrm{mmol}), 18 \mathrm{~mL}$ acetonitrile and a proper amount of $30 \%$ aqueous $\mathrm{H}_{2} \mathrm{O}_{2}$. The catalyst was dehydrated at $250{ }^{\circ} \mathrm{C}$ for $4 \mathrm{~h}$ before loading into the glass reactor. The progress of the reaction was monitored by analyzing the reaction samples at different time intervals by a gas chromatograph (ACME 6000 Series make, Youngin) equipped with a FID detector and a DB-Wax capillary column which is operated with oven temperature maintained at $105^{\circ} \mathrm{C} \sim 175^{\circ} \mathrm{C}$ programmed with a heating rate of $10^{\circ} \mathrm{C} / \mathrm{min}$. Conversion of cyclohexene and products selectivity was estimated based on the $\mathrm{GC}$ analysis.

\section{Results and Discussion}

Microwave synthesis of Ni-DHTP. XRD patterns of NiDHTP synthesized by MW method at different temperatures (a)

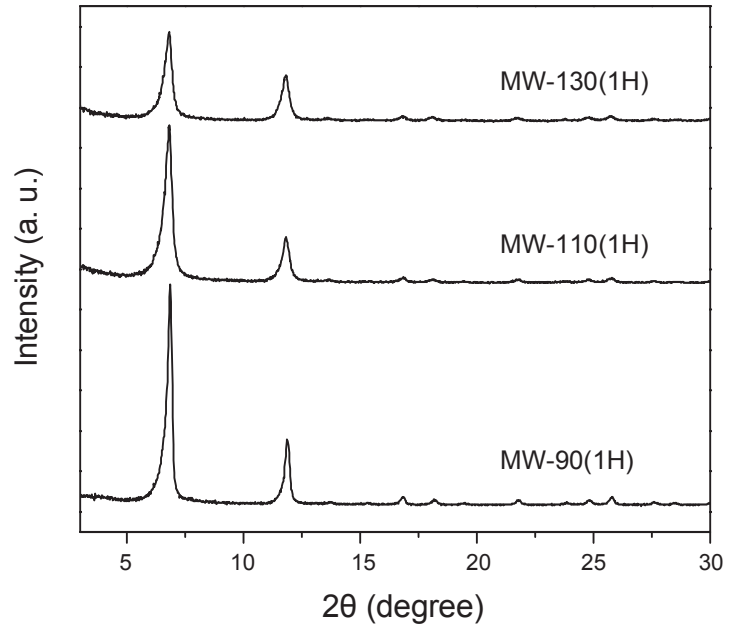

(b)

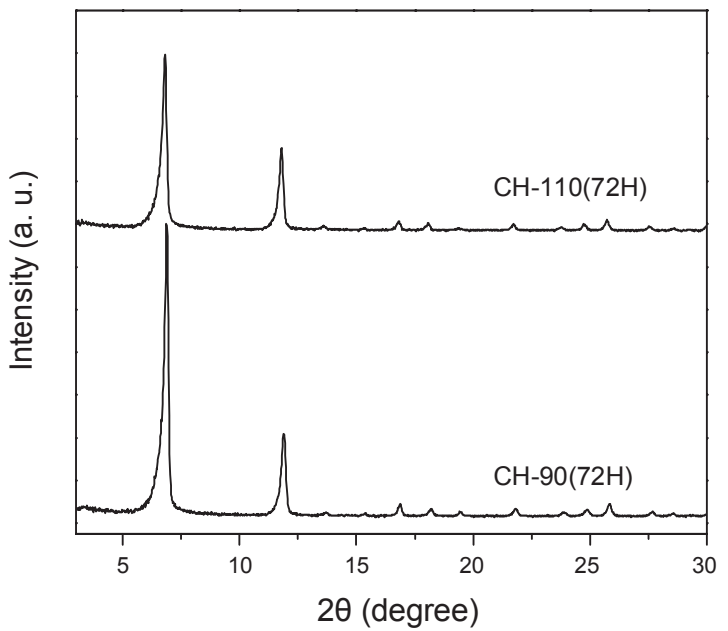

Figure 1. XRD patterns of Ni-DHTP synthesized by (a) MW and (b) $\mathrm{CH}$ methods at different temperatures.

in $1 \mathrm{~h}$ are depicted in Figure 1(a). It is seen that the samples synthesized at $90^{\circ} \mathrm{C}, 110^{\circ} \mathrm{C}$ and $130{ }^{\circ} \mathrm{C}$ show two well-resolved prominent diffraction peaks at $2 \theta$ of $6.9^{\circ}$ and $11.9^{\circ}$ which are characteristic peaks of trigonal (R-3) space group of Ni$\mathrm{CPO}-27^{11}$ indicating highly crystalline nature of the samples. The crystal sizes of the samples calculated from the Scherer equation are $28 \mathrm{~nm}(\mathrm{MW}-90(1 \mathrm{H})), 28 \mathrm{~nm}(\mathrm{MW}-110(1 \mathrm{H}))$ and $22 \mathrm{~nm}(\mathrm{MW}-130(1 \mathrm{H}))$, respectively. These values show domain sizes of primary particles, indicating that the sample synthesized at $90^{\circ} \mathrm{C}$ is well crystallized than that synthesized at $130{ }^{\circ} \mathrm{C}$. 
Moreover, the intensities of the corresponding peaks decrease (broadened) with increasing the synthesis temperature, which is attributed to rapid nucleation and growth of smaller crystals at higher temperature. Along with the smaller crystallite size, BET surface area $\left(913 \mathrm{~m}^{2} / \mathrm{g}\right)$ of the MW-130(1H) sample is notably less than those of other samples (Table 1), $1148 \mathrm{~m}^{2} / \mathrm{g}$ for MW-90(1H) and $1050 \mathrm{~m}^{2} / \mathrm{g}$ for MW-110(1H). Therefore, it could be concluded that Ni-DHTP synthesized at higher temperature by MW method results in higher crystallinity (smaller crystal size) compared to low temperatures. Similar observations with respect to XRD patterns have been obtained with the
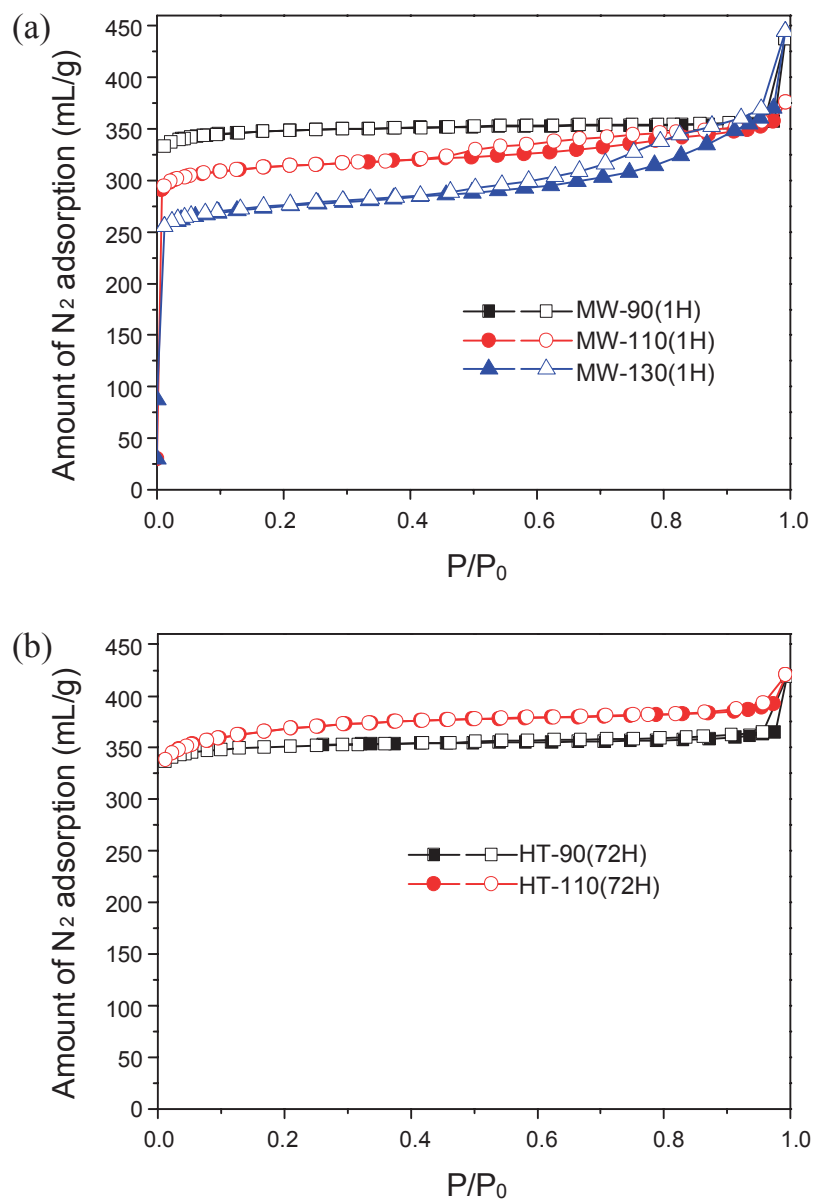

Figure 2. $\mathrm{N}_{2}$ adsorption-desorption isotherm of Ni-DHTP synthesized by (a) MW and (b) $\mathrm{CH}$ methods at different temperatures. Close and open symbols mean adsorption and desorption isotherms, respectively.
Ni-DHTP synthesized by CH method as shown in Figure 1(b). At $90{ }^{\circ} \mathrm{C}$ crystal growth is relatively slower than at $110{ }^{\circ} \mathrm{C}$ in $\mathrm{CH}$ conditions because of lower thermal activation energy. Further evidences to support XRD observations will be discussed in BET and SEM analysis.

Figure 2 illustrates the nitrogen adsorption-desorption isotherms at $-196{ }^{\circ} \mathrm{C}$ showing the pore characteristics of Ni-DHTP synthesized at different temperatures. All samples show type-I isotherms with a steep increases in adsorption at $\mathrm{p} / \mathrm{p}$ of $\sim 0.0$, due to rapid filling of nitrogen in the well-defined micropores of Ni-DHTP. Texture properties of all the Ni-DHTP samples synthesized by MW and $\mathrm{CH}$ methods are summarized in Table 1. It is seen that increase in synthesis temperature from $90{ }^{\circ} \mathrm{C}$ to $110^{\circ} \mathrm{C}$ with $\mathrm{CH}$ method, the surface area and pore volumes are increased because of smaller size of crystals. However, in MW irradiation condition surface area and pore volumes decreased with increase in temperature due to the rapid crystallization at higher temperature resulted in lower crystallinity. The main difference between MW and CH synthesis method is the synthesis time, which is $72 \mathrm{~h}$ with $\mathrm{CH}$, while it is $1 \mathrm{~h}$ or even shorter with $\mathrm{MW}$ in the same range of temperatures. At $\mathrm{CH}$ condition, reaction time of $72 \mathrm{~h}$ is enough to form the well crystalline NiDHTP; therefore higher temperature resulted in smaller particle size and higher surface area than lower temperature. However, in MW irradiation condition nucleation and crystallization was controlled within one hour, therefore temperature is more influencing on crystallinity than $\mathrm{CH}$. Microwave irradiation time is also allowed to increase the surface area as seen in Table 1. To understand the microwave effect on nucleation and crystal growth the study made has been discussed in further text.

To know the effect of temperature on the morphological changes, SEM photographs of Ni-DHTP synthesized by MW method at different temperatures are shown in Figure 3. NiDHTP resulted in small crystal sizes in aggregate form. This is clear from the SEM photographs that the crystal growth becomes finely dispersed at $130{ }^{\circ} \mathrm{C}(80 \mathrm{~nm}$ aggregate $)$. While, the crystal sizes of the Ni-DHTP synthesized by MW method at $90{ }^{\circ} \mathrm{C}(560 \mathrm{~nm}$ aggregate $)$ and $110{ }^{\circ} \mathrm{C}$ (160 nm aggregate) are slightly higher than that of $130{ }^{\circ} \mathrm{C}$ synthesized material. These results are consistent with $\mathrm{XRD}$ and BET data as shown in Figure 1 and Figure 2, respectively. Similarly, Figure 4 shows the pronounced effect of temperature on the growth of crystal size. Both the MW and CH methods led to the formation of highly dispersed crystals of Ni-DHTP, while MW has advantages over $\mathrm{CH}$ method with respect to synthesis time and gave highly

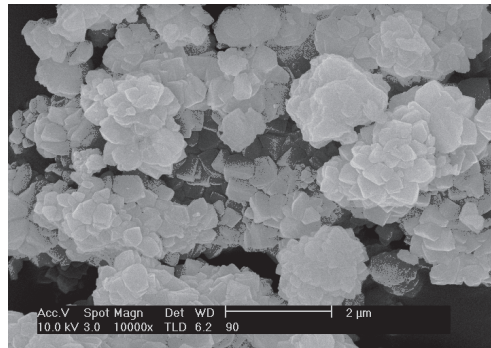

(a)

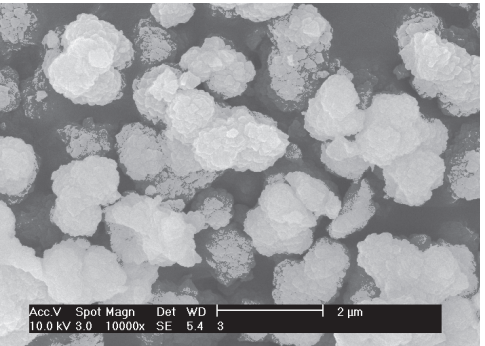

(b)

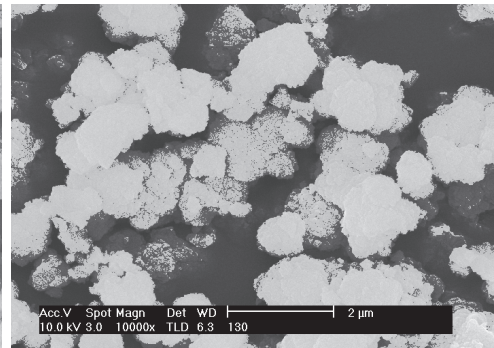

(c)

Figure 3. SEM images of Ni-DHTP synthesized by MW method at different temperatures: (a) MW-90(1H), (b) MW-110(1H) and (c) MW-130(1H). 


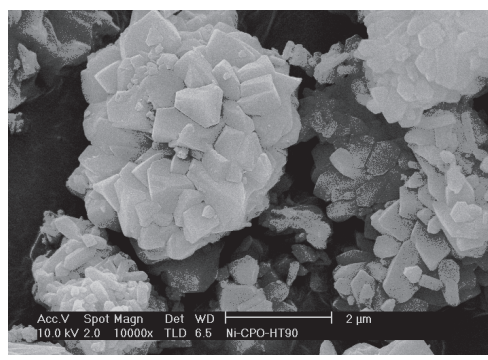

(a)

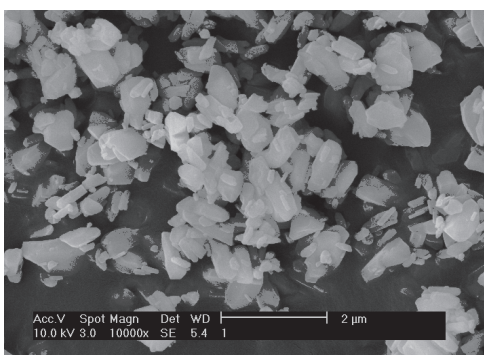

(b)

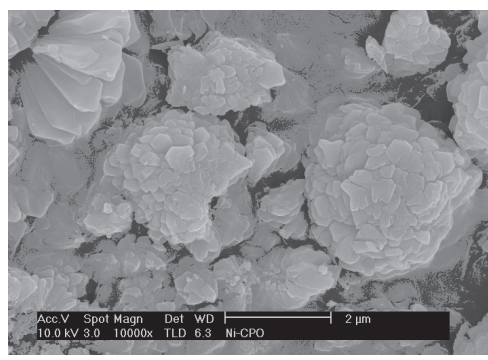

(c)

Figure 4. SEM images of Ni-DHTP synthesized by CE method at different temperatures: (a) CH-90(72H), (b) CH-110(72H) and (c) CH-130(72H).

dispersed crystal sizes. Moreover, the crystal sizes obtained as aggregate with MW method even at lower temperatures are much smaller.

Effect of irradiation time on XRD patterns of Ni-DHTP washed with ethanol synthesized by MW method is as shown in Figure 5. The crystal size as a function irradiation time, it was found that crystal size of MW synthesized at $110{ }^{\circ} \mathrm{C}$ in aggregate forms, $2 \mathrm{~min}-\mathrm{MW} 110^{\circ} \mathrm{C}(28 \mathrm{~nm}), 10 \mathrm{~min}-\mathrm{MW}$ $110^{\circ} \mathrm{C}(28 \mathrm{~nm})$ and $1 \mathrm{~h}-\mathrm{MW} 110^{\circ} \mathrm{C}(22 \mathrm{~nm})$, respectively. The sizes of polycrystal domain were not much affected because of smaller irradiation times and even at 2 min irradiation, the crystal size is $28 \mathrm{~nm}$, which is highly dispersed into smaller cry-

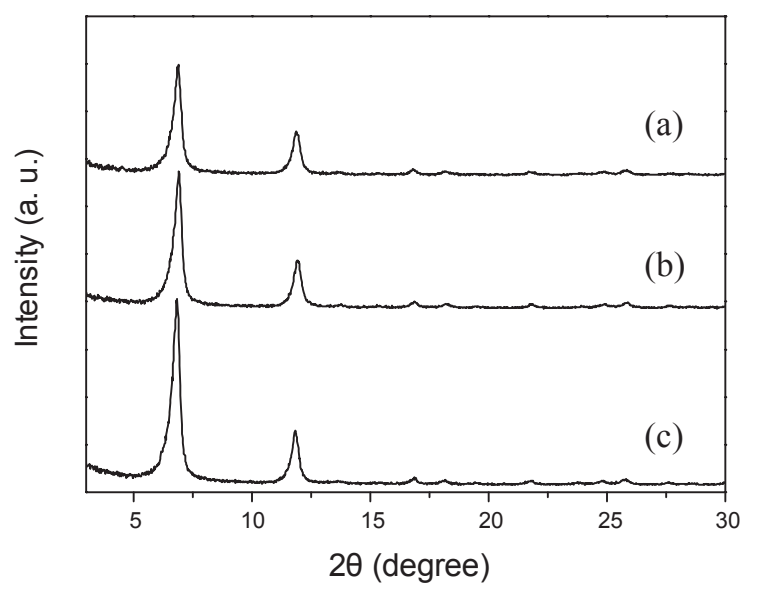

Figure 5. XRD patterns of Ni-DHTP synthesized by MW method at different irradiation times: (a) MW-110(2M), (b) MW-110(10M), and (c) MW-110(1H). stals. However, the yields remained the same $(\sim 60 \%)$. Figure 6 shows the SEM images of the MW synthesized Ni-DHTP samples at $110{ }^{\circ} \mathrm{C}$ with different irradiation time intervals in the range $2 \mathrm{~min}$ to $1 \mathrm{~h}$. It is seen that irradiation time has no significant influence on the crystal growth recorded in $10 \mathrm{~nm}$ to $1 \mu \mathrm{m}$ range, which reached high dispersity even in 2 minute. These observations are supported by XRD diffractions patterns as seen in Figure 5.

Purified crystalline MOFs with high porosity and surface areas are critically essential in terms of chemical and physical properties and of applications. ${ }^{18}$ Figure 7 shows the FT-IR spectra of the Ni-DHTP samples synthesized by MW irradiation

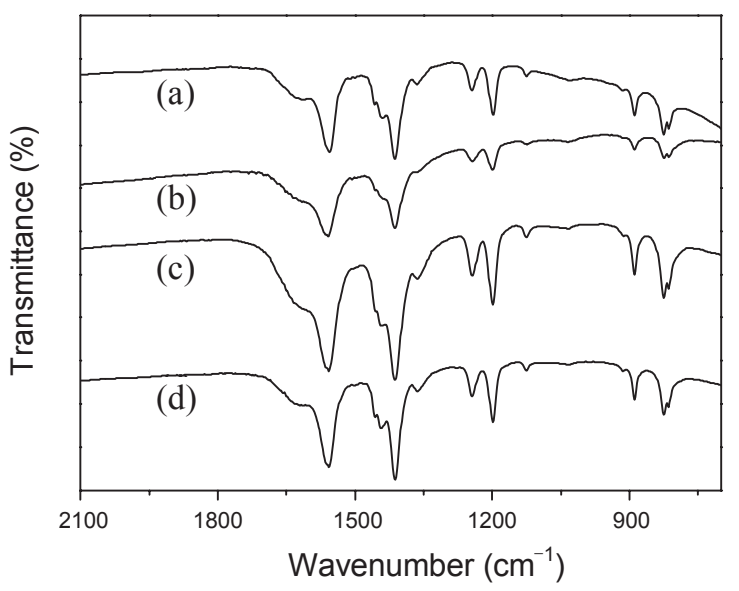

Figure 7. FT-IR spectra of Ni-DHTP synthesized by MW and CH methods: (a) CH-110(72H), (b) MW-110(2M), (c) MW-110(10M), and (d) MW-110(1H).

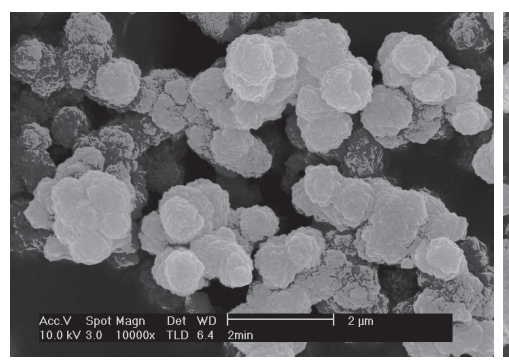

(a)

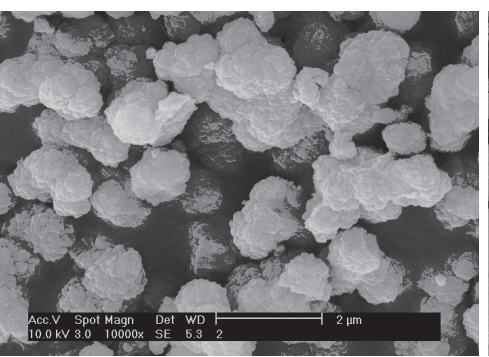

(b)

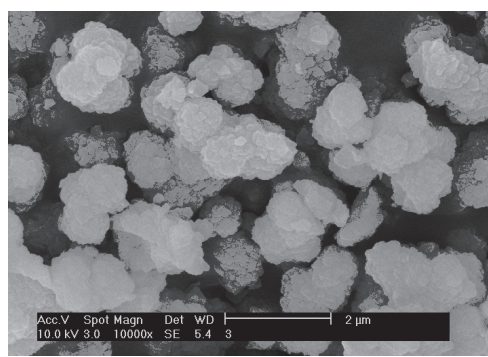

(c)

Figure 6. SEM image of synthesized by MW method samples at different irradiation times: (a) MW-110(2M), (b) MW-110(10M), and (c) MW-110(1H). 
Table 2. Oxidation of cyclohexene with $\mathrm{H}_{2} \mathrm{O}_{2}$ over Ni-DHTP (MW-110(1H)) synthesized by $\mathrm{MW}^{a}$

\begin{tabular}{ccccccc}
\hline \multirow{2}{*}{$\begin{array}{c}\mathrm{H}_{2} \mathrm{O}_{2} / \text { Cyclohexene } \\
\text { (molar ratio) }\end{array}$} & $\begin{array}{c}\text { Cyclohexene } \\
\text { Conv. }(\%)\end{array}$ & TOF $^{b}$ & & \multicolumn{4}{c}{ Product selectivity (\%) } \\
\cline { 5 - 7 } & & & Cyclo-oxide & Cyclo-one & Cyclo-ol & Cyclo-diol \\
\hline 1 & 7.8 & 1.2 & 34.7 & 21.7 & 43.6 & - \\
3 & 63.6 & 9.9 & 36.2 & 21.4 & 33.1 & 9.3 \\
\hline
\end{tabular}

${ }^{a}$ Reaction conditions: Catalyst $=0.1 \mathrm{~g}$, Temp. $=60^{\circ} \mathrm{C}$ and Time $=8 \mathrm{~h} .{ }^{b} \mathrm{TOF}$ (Turnover frequency) $=$ mole of cyclohexene converted per mole of catalyst per hour. ${ }^{c}$ Legend: Cyclo-oxide $=$ Cyclohexene oxide; Cyclo-one $=2$-cycolhexene-1-one; Cyclo-ol = 2-cycolhexene-1-ol; Cyclo-diol = 1,2-cyclohexanediol.

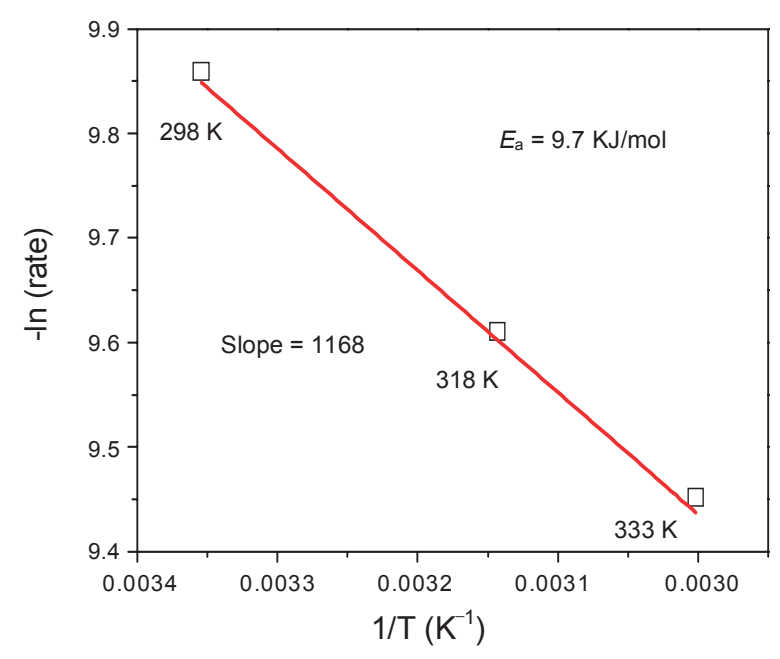

Figure 8. Arrhenius graph for the oxidation reaction.

at temperatures in the range of $90{ }^{\circ} \mathrm{C}$ to $110{ }^{\circ} \mathrm{C}$ with different irradiation times of $2 \mathrm{~min}$ to $1 \mathrm{~h}$. After ethanol treatment, the unreacted 2,5-dihydroxyterephthalic acid and metal ions were almost occluded in crystalline Ni-DHTP. From the above results, we can conclude that the optimum synthesis conditions to get highly crystalline Ni-DHTP from MW method are reaction temperature of $110{ }^{\circ} \mathrm{C}$ and irradiation time of $1 \mathrm{~h}$. Further studies on catalytic application have been investigated with NI-DHTP, MW-110 $(1 \mathrm{H})$ in the oxidation of cyclohexene using $\mathrm{H}_{2} \mathrm{O}_{2}$ as an oxidant in liquid phase conditions at moderate reaction conditions.

Cyclohexene oxidation. In the oxidation of cyclohexene using $\mathrm{H}_{2} \mathrm{O}_{2}$, four products such as cyclohexene oxide, 2-cyclohexen-1-one, 2-cyclo-hexen-1-ol and 1,2-cyclohexanediol, respectively were formed as shown in Scheme 1. Results on the oxidation of cyclohexene carried out using aqueous $\mathrm{H}_{2} \mathrm{O}_{2}$ over Ni-DHTP catalyst presented in Table 2 . It is seen that convertsion of cyclohexene increased with increase in $\mathrm{H}_{2} \mathrm{O}_{2} /$ cyclohexe mole ratio from 1 to 3 . Highest conversion of $75.4 \%$ cyclohexene is obtained at $\mathrm{H}_{2} \mathrm{O}_{2}$ /cyclohexe mole ratio of 3 with a TOF of 11.8 (mole cyclohexene converted per mole of catalyst per h) at $60{ }^{\circ} \mathrm{C}$ in $8 \mathrm{~h}$. However, the selectivities for cyclohexene oxide and 2-cyclohexene-1-one remained almost the same in all $\mathrm{H}_{2} \mathrm{O}_{2}$ /cyclohexene mole ratio varied from 1 to 3 , while the selectivity for 2-cyclohexene-1-ol was found to be maximum (43.6\%), with $\mathrm{H}_{2} \mathrm{O}_{2}$ /cyclohexene mole ratio of 1. Higher amount of $\mathrm{H}_{2} \mathrm{O}_{2}$ in the reaction mixture decreased the selectivity for 2-cyclohexene-1-ol. This is expected since increase in $\mathrm{H}_{2} \mathrm{O}_{2}$ /

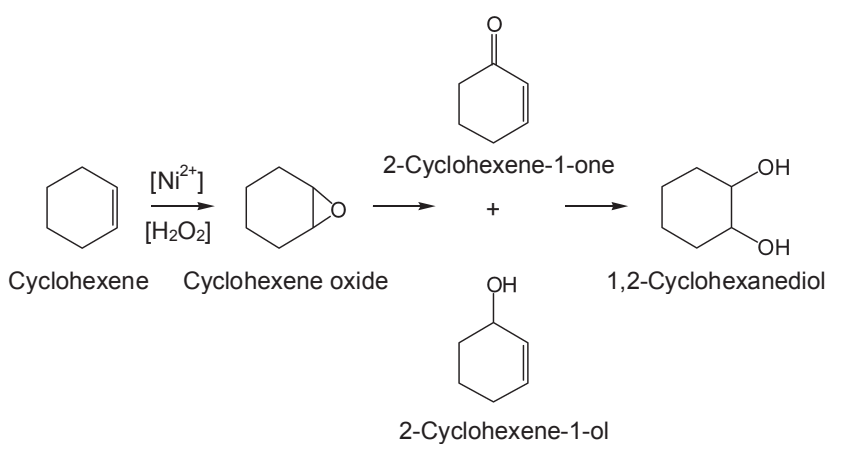

Scheme 1. Oxidation of cyclohexene

cyclohexene mole ratio, where higher $\mathrm{H}_{2} \mathrm{O}_{2}$ available leads to further oxidation to give 1,2-cyclohexenediol as the final product of cyclohexene oxidation. Therefore, it is concluded that the optimum reaction conditions to get selectively 2-cyclohexene-1-ol would be $\mathrm{H}_{2} \mathrm{O}_{2} /$ cyclohexene mole ratio of $1,60{ }^{\circ} \mathrm{C}$ and $8 \mathrm{~h}$ reaction time. Under the reaction conditions, we also checked and found the absence of decomposition of $\mathrm{H}_{2} \mathrm{O}_{2}$ (by titration with $\mathrm{Na}_{2} \mathrm{~S}_{2} \mathrm{O}_{3}$ solution) and the efficiency was maximum $(100 \%)$ and fully utilized in the oxidation reaction. Cyclohexene oxide is the primary product of the oxidation reaction (Scheme 1) and it is getting converted into to other products either through parallel/ or successive reactions steps finally to give 1,2-cyclohexanediol as the end product. It is seen from Table 2 results that maximum yields of 2-cyclo-hexen-1-ol are formed with $\mathrm{H}_{2} \mathrm{O}_{2}$ /cyclohexene mole ratio of 1 . However, with increase in $\mathrm{H}_{2} \mathrm{O}_{2}$ /cyclohexene mole ratio as 2 or 3 , the yields of 2-cyclo-hexen-1-ol are drastically decreased and led to the formation of 1,2-cyclohexanediol. As we previously reported that nickel phosphates VSB-5 with $\mathrm{Ni}^{2+}$ species in the frameworks showed a shape-selectivity for epoxidation of cyclic olefins, ${ }^{41}$ the unsaturated Ni(II) sites presented in Ni-DHTP is thought to be possible active species for expoxidation of cyclic olefins. Moreover, when we used $\mathrm{H}_{2} \mathrm{O}_{2}$ as the oxidant, the soluble nickel salts including $\mathrm{NiCl}_{2} \cdot 6 \mathrm{H}_{2} \mathrm{O}$ and $\mathrm{Ni}(\mathrm{ac})_{2} \cdot 4 \mathrm{H}_{2} \mathrm{O}$ showed the very low cyclohexene conversion of $21.3 \%$ and $27.7 \%$, respectively, indicating that nickel salts are ineffective in epoxidation using $\mathrm{H}_{2} \mathrm{O}_{2}$. However, further detail study is needed to clarify how nickel species catalyze the epoxidation reaction. The activities of Ni-DHTP synthesized by MW at different temperatures are also compared.

To confirm the effect of temperature on the rate of oxidation and to evaluate activation energy $\left(\Delta E_{\mathrm{a}}\right)$, the oxidation of cyclohexene with aqueous $\mathrm{H}_{2} \mathrm{O}_{2}$ was carried out with the best $\mathrm{Ni}$ - 
Table 3. Effect of temperature on conversion and products selectivities by Ni-DHTP (MW-110(1H))

\begin{tabular}{|c|c|c|c|c|c|c|}
\hline \multirow{2}{*}{$\begin{array}{l}\text { Temp. } \\
\left({ }^{\circ} \mathrm{C}\right)\end{array}$} & \multirow{2}{*}{$\begin{array}{c}\text { Cyclohexene } \\
\text { Conv. }(\%)\end{array}$} & \multirow{2}{*}{$\begin{array}{c}\text { Rate } \\
(\text { mole } / \mathrm{min}) \times 10^{-5}\end{array}$} & \multicolumn{4}{|c|}{ Products selectivity $(\%)^{\mathrm{c}}$} \\
\hline & & & Cyclo-oxide & Cyclo-one & Cyclo-ol & Cyclo-diol \\
\hline 25 & 50.2 & 5.2 & 12.8 & 29.3 & 44.3 & 13.6 \\
\hline 45 & 66.5 & 6.9 & 48.9 & 9.5 & 14.9 & 26.7 \\
\hline 60 & 75.4 & 7.9 & 39.7 & 18.7 & 27.2 & 14.4 \\
\hline
\end{tabular}

Conditions: $\mathrm{H}_{2} \mathrm{O}_{2} /$ Cyclohexene $=3$ (mole ratio), catalyst $=0.1 \mathrm{~g}$, and time $=8 \mathrm{~h} .{ }^{c}$ Legend: Cyclo-oxide $=$ Cyclohexene oxide; Cyclo-one $=2$-cycolhexene-1-one; Cyclo-ol = 2-cycolhexene-1-ol; Cyclo-diol = 1, 2- cyclohexanediol.

DHTP, MW-110(1H) catalyst in the range of temperatures 25 to $60{ }^{\circ} \mathrm{C}$. The results along with reaction conditions are listed in Table 3. It is seen from the results that conversion of cyclohexene is strongly dependent on reaction temperature. The rate (mole of cyclohexene converted per min) increased with increase in temperature. From the Arrhenius plot, the activation energy was calculated to be $9.7 \mathrm{~kJ} / \mathrm{mol}$.

Catalyst leaching was studied at $65^{\circ} \mathrm{C}$ and at room temperature under similar conditions of oxidation $\left(\mathrm{H}_{2} \mathrm{O}_{2} /\right.$ cyclohexene mole ratio 3 , catalyst $=0.1 \mathrm{~g}$, temp. $=60^{\circ} \mathrm{C}$ and time $=8 \mathrm{~h}$ to establish catalyst leaching into the reaction mixture and determine whether it is homogeneously or heterogeneously catalyzed oxidation). After the $4 \mathrm{~h}$ reaction, the catalyst was separated by filtration from both the set of experiments. These filtrates were subjected for further reaction without the catalyst. It was noticed that the conversion of cyclohexene increased with the filtrate separated from the oxidation reaction carried out at $65^{\circ} \mathrm{C}$ confirming the catalyst leaching. However, the filtrate at room temperature oxidation experiment did not show any increase in cyclohexene conversion, which confirms that the catalyst is not leached at room temperature and the oxidation proceeds in heterogeneous path. So, we suggest that the Ni-CPO-27 catalyst is most suitable for room temperature or low temperature oxidation of cyclohexene, wherein this could be used as a heterogeneous catalyst.

\section{Conclusions}

Metal-Organic Framework (MOF), Nickel dihydroxyterephthalate (Ni-DHTP) containing coordination complex of nickel ions and 2,5-dihydroxyterephthalic acid could be synthesized more efficiently in shorter irradiation times by MW method compared to the $\mathrm{CH}$ method. MW method gave highly crystalline and dispersed Ni-DHTP MOF at $110^{\circ} \mathrm{C}$ crystals $(22.5 \mathrm{~nm}$ aggregates) within $1 \mathrm{~h}$. We have demonstrated in this report that Ni-DHTP synthesized by MW method showed excellent catalytic activity in cyclohexene oxidation using aqueous $\mathrm{H}_{2} \mathrm{O}_{2}$ oxidant with higher selectivity for cyclohexene oxide and 2-cyclo-hexen-1-ol. Hence, we recommend that Ni-DHTP synthesized by MW could be used for the oxidation of other monoolefins to have controlled and selective oxidation for the desired products.

Acknowledgments. This work was supported by the National Research Foundation of Korea (NRF) funded by the Ministry of Education, Science and Technology (KN-0942) and partly by the international collaboration program (KICOS). To Prof.
Nak Han Jang, this work was supported by the research grant of the Kongju National University in 2008. Dr. Shiva B. Halligudi acknowledges KOFST for awarding visiting scientist fellowship under Brain Pool program at KRICT, Daejeon, Korea.

\section{References}

1. Yaghi, O. M.; O'Keeffe, M.; Ockwig, N. W.; Chae, H. K.; Eddaoudi, M.; Kim, J. Nature 2003, 423, 705.

2. Kitagawa, S.; Matsuda, R. Coord. Chem. Rev. 2007, 251, 2490.

3. Férey, G. Chem. Soc. Rev. 2008, 37, 191.

4. Hong, M. C.; Zhao, Y. J.; Su, W. P.; Cao, R.; Fujita, M.; Zhou, Z. Z.; Albert, S. C. J. Am. Chem. Soc. 2000, 122, 4819.

5. Kepert, C. J.; Prior, T. J.; Rosseinsky, M. J. J. Am. Chem. Soc. 2000, $122,5158$.

6. Zhao, X.; Xiao, B.; Fletcher, A.; Thomas, K. M.; Bradshaw, D.; Rosseinsky, M. J. Science 2004, 306, 1012.

7. Latroche, M.; Surblé, S.; Serre, C.; Mellot-Draznieks, C.; Llewellyn, P. L.; Lee, J. -H.; Chang, J.-S.; Jhung, S. H.; Férey, G. Angew. Chem. Int. Ed. 2006, 45, 8227.

8. Hwang, Y. K.; Hong, D.-Y.; Chang, J.-S.; Jhung, S. H.; Seo, Y.-K.; Kim, J.; Vimont, A.; Daturi, M.; Serre, C.; Férey, G. Angew. Chem. Int. Ed. 2008, 47, 4144.

9. Horcajada, P.; Chalati, T.; Serre, C.; Gillet, B.; Sebrie, C.; Baati, T.; Eubank J.; Heurtaux, D.; Clayette, P.; Kreuz, C.; Chang, J.-S.; Hwang, Y. K.; Bories, P.-N.; Cynober, L.; Gil, S.; Férey, G. Nat. Mater. 2010, 9, 172.

10. Kitagawa, S.; Kitaura, R.; Noro, S.-I. Angew. Chem. Int. Ed. 2004, 43, 2334

11. Dietzel, P. D. C.; Panella, B.; Hirscher, M.; Blom, R.; Fjellvåg, H. Chem. Commun. 2006, 959.

12. Dietzel, P. D. C.; Johnsen, R. E.; Blom, R.; Fjellvåg, H. Chem. Eur. J. 2008, 14, 2389.

13. Vitillo, J. G.; Regli, L.; Chavan, S.; Ricchiardi, G.; Ricchiardi, G.; Spoto, G.; Dietzel, P. D. C.; Bordiga, S.; Zecchina, A. J. Am. Chem. Soc. 2008, 130, 8383.

14. Caskey, S. R.; Wong-Foy, A. G.; Matzger, A. J. J. Am. Chem. Soc. 2008, 130, 10870.

15. Dietzel, P. D. C.; Johnsen, R. E.; Fjellvåg, H.; Bordiga, S.; Groppo, E.; Chavan, S.; Blom, R. Chem. Commun. 2008, 5125.

16. Mckinlay, A. C.; Xiao, B.; Wragg, D. S.; Wheatley, P. S.; Megson, I. L.; Morris, R. E. J. Am. Chem. Soc. 2008, 130, 10440.

17. Rosi, N. L.; Kim, J.; Eddaoudi, M.; Chen, B.; O’Keffe, M.; Yaghi, O. M. J. Am. Chem. Soc. 2005, 122, 1504.

18. Hong, D.-Y.; Hwang, Y. K.; Serre, C.; Férey, G.; Chang, J.-S. Adv. Funt. Mater. 2009, in press.

19. Seo, Y.-K.; Hundal, G.; Jang, I. T.; Hwang, Y. K.; Jun, C.-H.; Chang, J.-S. Microporous Mesoporous Mater. 2009, 119, 331.

20. Hwang, Y. K.; Chang, J.-S.; Park, S.-E.; Kim, D. S.; Kwon, Y.-U.; Jhung, S. H.; Hwang, J.-S.; Park, M. S. Angew. Chem. Int. Ed. 2005, 44,556 .

21. Komarneni, S.; Rajha, R. K.; Katuski, H. Mater. Chem. Phy. 1999, 61,50 .

22. Tompsett, G.; Conner, W. C.; Yngvesson, K. S. Chem. Phys. Chem. 2006, 7, 296. 
23. Park, S.-E.; Chang, J.-S.; Hwang, Y. K.; Kim, D. S.; Jhung, S. H.; Hwang, J.-S. Catal. Survey Asia 2004, 8, 91.

24. Hwang, Y. K.; Chang, J.-S.; Kwon, Y.-U.; Park, S.-E. Micropor. Mesopor. Mater. 2004, 68, 21.

25. Jhung, S. H.; Chang, J.-S.; Hwang, Y. K.; Park, S.-E. J. Mater. Chem. 2004, 14, 280.

26. Hwang, Y. K.; Jin, T.-H.; Kim, J. M.; Kwon, Y.-U.; Park, S.-E.; Chang, J.-S. J. Nanosci. Nanotechnol. 2006, 6, 1786.

27. (a) Jhung, S. H.; Lee, J.-H.; Yoon, J. W.; Serre, C.; Férey, G.; Chang, J.-S. Adv. Mater. 2007, 19, 121. (b) Haque, E.; Khan, N. A.; Park, J. H.; Jhung, S. H. Chem. Eur. J. 2010, 16, 1046.

28. (a) Jhung, S. H.; Lee, J.-H.; Forster, P. M.; Férey, G.; Cheetham, A. K.; Chang, J.-S. Chem. Eur. J. 2006, 12, 7899. (b) Khan, N. A.; Jhung, S. H. Crystal Growth Des. 2010, 10, 1860.

29. (a) Ni, Z.; Masel, R. I. J. Am. Chem. Soc. 2006, 128, 12394. (b) Khan, N. A.; Haque, E.; Jhung, S. H. Phys. Chem. Chem. Phys. 2010, 12, 2625.

30. Parnham, E. R.; Morris, R. E. Acc. Chem. Res. 2007, 40, 1005.

31. Kesanli, B.; Lin, W. B. Coord. Chem. Rev. 2003, 246, 305.
32. Cheethan, A. K.; Rao, C. N. R.; Peller, R. K. Chem. Commun. 2006, 4780.

33. Muller, U.; Schubert, M. M.; Teich, F.; Puetter, H.; SchieericArndt, K.; Pastre, J. J. Mater. Chem. 2006, 16, 626.

34. Maspoch, D.; Ruiz-Molina, D.; Veciana, J. Chem. Soc. Rev. 2007, 36,770

35. Muller, U.; Schubert, M. M.; Yaghi, O. M. Handbook of Heterogeneous Catalysis; Knozinger, Ertl. H., Schuth, F., Weitkamp, J., Eds.; Wiley-VCH: 2008; 247.

36. Hwang, Y. K.; Hong, D.-Y.; Chang, J.-S.; Kim, H. S.; Jhung, S. H.; Serre, C.; Ferey, G. Appl. Catal. A 2009, 358, 249.

37. Férey, G. Chem. Soc. Rev. 2008, 37, 191.

38. Seo, J. S.; Whang, D.; Lee, H.; Jun, S. I.; Oh, J.; Jeon, Y. J.; Kim, K. Nature 2000, 404, 982.

39. Wu, C.-D.; Lin, W. Angew. Chem. Int. Ed. 2007, 46, 1075.

40. Alaerts, L.; Séguin, E.; Poelman, Thibault-Starzyk, H.; F.; Jacobs, P. A.; De Vos, D. E. Chem. Eur. J. 2006, 12, 7353.

41. Jhung, S. H.; Lee, J.-H.; Cheetham, A. K.; Férey, G.; Chang, J.-S. J. Catal. 2006, 239, 97. 